\title{
Decentralized Control Strategies of Adjacent Building Structures Vibration under Earthquake Excitation
}

\author{
Xiaofang Kang $\mathbb{D}^{1,2,3}$ Peipei Zhang, ${ }^{1}$ Yiwei Zhang, ${ }^{1}$ Dawei Man, ${ }^{1,2,3}$ Qinghu Xu, ${ }^{1,2,3}$ \\ Xianzeng Shi, ${ }^{1,4}$ Yu Zhang, ${ }^{5}$ and Guanghui Xia $\mathbb{D}^{1,2,3}$ \\ ${ }^{1}$ School of Civil Engineering, Anhui Jianzhu University, Hefei 230601, China \\ ${ }^{2}$ Prefabricated Building Research Institute of Anhui Province, Hefei 230601, China \\ ${ }^{3}$ BIM Engineering Center of Anhui Province, Hefei 230601, China \\ ${ }^{4}$ College of Civil and Transportation Engineering, Hohai University, Nanjing 210098, China \\ ${ }^{5}$ School of Engineering, Anhui Agricultural University, Hefei 230036, China \\ Correspondence should be addressed to Guanghui Xia; xgh@ahjzu.edu.cn
}

Received 5 March 2021; Revised 30 March 2021; Accepted 11 April 2021; Published 26 April 2021

Academic Editor: M. Syed Ali

Copyright (c) 2021 Xiaofang Kang et al. This is an open access article distributed under the Creative Commons Attribution License, which permits unrestricted use, distribution, and reproduction in any medium, provided the original work is properly cited.

\begin{abstract}
A decentralized control scheme can effectively solve the control problem of civil engineering structure vibration under earthquake. This paper takes a research into the decentralized control scheme of adjacent buildings when the earthquake happens. It combines overlapping decentralized control method and linear matrix inequality (LMI) with $H_{\infty}$ control algorithm and puts forward the overlapping decentralized $H_{\infty}$ control method. A simplified dynamical model of structural vibration control has been established considering the topology structural features of adjacent buildings. The $H_{\infty}$ control algorithm is applied into each dynamically different subsystems and can be also served as the decentralized $H_{\infty}$ controllers. Therefore, by contracting decentralized $H_{\infty}$ controllers to original state space, overlapping decentralized $H_{\infty}$ controllers are obtained. In this manner, the adjacent buildings' structure model is analyzed in terms of simulation and calculation which provides a comprehensive insight into vibration control. The results show that the centralized control, the decentralized control, and the overlapping decentralized control, based on linear matrix inequality, can be nearly effective in cases above satisfactorily. Besides, it can also reduce the computational cost as well as increase the flexibility of controller design.
\end{abstract}

\section{Introduction}

In recent years, many scholars have carried out related studies on vibration control of adjacent building structures [1-3]. The investigations on the vibration control of two adjacent building structures under seismic load by means of theoretical simulation and experiment have been conducted, which compared the structural vibration response of two steel towers under different natural frequency and damping ratio and different combination spacing and seismic wave excitation [4]. Studies have been performed on the seismic performance of adjacent building structures under connected isolation devices, focusing on different isolation measures of the same building structures and the vibration control effect of different building structures under the same isolation measures specifically [5]. Coupling the additional damping devices of adjacent building structures is a practical and effective method to reduce the seismic response of structures. The nonlinear hysteretic damping device has been applied to investigate the vibration control of two adjacent building structures under random earthquake action [6]. Seismic experiments have been conducted on the model which consisted of two adjacent building structures, a 5-story steel frame structure and a 6-story steel frame structure, and have used a liquid viscous damper device as an example [7]. The stochastic average method has been used which solved the stochastic differential equation of the structural vibration in the reduced order model case, and the stochastic optimal coupling control of adjacent building structures has been studied [8]. Two adjacent multidegree of freedom building structures have been taken as examples, and friction dampers have been set between the building structures to realize the seismic performance [9]. Viscoelastic dampers (VEDs) between adjacent building 
structures to reduce structural vibration response under earthquake action have been installed [10]. Besides, investigations on the seismic performance of connected building structures affected by the stiffness of viscoelastic dampers have been studied [11]. Nonlinear hysteresis equipment installed between two adjacent building structures to study the passive optimization control of the structure has been adopted [12]. The connected control method (CCM) has been used to study the vibration control of adjacent building structures under seismic excitation, focusing on the influence of building height and CCM coupling position on the structural vibration control performance. Adjacent high-rise building structures are vulnerable to get damaged when excited by strong earthquakes [13]. The collision between high-rise building structures during earthquake by setting MR damper between adjacent building structures has been figured out, and the vibration control problems of adjacent high-rise building structures under earthquake action by adopting passive closing, passive opening, and semiactive control strategies have been analyzed [14]. Exponential sampled-data control for T-S fuzzy systems has been applied to Chua's circuit [15]. Sampling data control theory has the characteristics of high precision, high reliability, and effective interference suppression in the control system. In addition, the digital controller is easier to adjust than the analog controller in terms of flexibility provided that the problem has been modified to accommodate the design changes within the sampling data control strategy $[16,17]$. Some advanced control concepts have been well applied in the vibration control system of building structure. Linear matrix inequality (LMI) and Takagi-Sugeno (T-S) fuzzy submodels have been applied to the sampling data control of nonlinear systems $[18,19]$. Moreover, the stability of the control system has become a research heated issue. Based on the fuzzy model-based control method and linear matrix inequality (LMI) technique, many scholars have derived several new conditions to make sure the stability of the controlled system [20-22].

When the civil building is subjected to external load, such as earthquake and wind, they will cause damage to the structure. Therefore, it is necessary to control the vibration of the structure in order to reduce or even eliminate the vibration as far as possible in an effective way. Decentralized control is an ideal strategy to solve the vibration control problem of building structure with multiple degrees of freedom. The LQR control algorithm to study the vibration control problem of connected multistructures has been proposed [23]. Linear matrix inequality (LMI) has been applied to put forward the $H_{\infty}$ control method for decentralized building structures [24]. To take the stability of complex dynamic network systems into consideration, Lyapunov-Krasovskii stability theorem and linear matrix inequality (LMI) have been applied in the controller design of the system [25]. And the fuzzy logic theory with the iterative learning control algorithm has been proposed in a decentralized form for vibration control of high-rise building structure under earthquake action [26]. The discovery of the maximum relative displacement coefficient of adjacent building structures has been taken, which is subjected to earthquake action, and a method for calculating the counterpart has been presented in elastic and inelastic states [27]. Based on the LQG output feedback control algorithm, the vibration control of adjacent building structures under earthquake action has been analyzed [28]. However, there are few studies on the overlapping and decentralized control methods to solve the vibrate counterpart. Overlapping decentralized control strategy is that the whole structure vibration control system is partitioned into two multiple overlapping subsystems, which is according to certain rules, and each subsystem is used to control independently by local information.

To discuss the control effect of decentralized control strategy under seismic excitation, in the first step, the basic theory of the adjacent structure connection system is established as follows in this paper. Secondly, the overlapping decentralized control method, linear matrix inequality (LMI), and $\mathrm{H}_{\infty}$ control algorithm are combined comprehensively to realize the effect satisfactorily, and an overlapping decentralized $H_{\infty}$ control method based on LMI is proposed. Finally, the centralized control, decentralized control, and overlapping decentralized control based on linear matrix inequality (LMI) are designed for the structural vibration response of two adjacent buildings under seismic excitation, which provides the numerical presentation for analysis results. Overlapping decentralized control strategy provides a novel method to solve the vibration control problem of adjacent buildings, and the strategy reduces the calculation cost as well as increases the flexibility of controller design.

\section{Basic Theory of Adjacent Structure Connection System}

The mathematical model for calculating the dynamic data of the system $S$ connected with adjacent structures is shown in Figure 1. The whole system $S$ is composed of P-column substructures $S^{(1)}, \ldots, S^{(R)}$. Each substructure $S^{(j+1)}$ mass spring damping system is made up of $n_{j}$ degrees of freedom. And system $L^{(j)}$ connects between adjacent substructures $S^{(j)}$ and $S^{(j+1)}$. Now, this section needs to find a second-order motion equation that can properly describe the overall motion characteristics of the connected building structures as follows:

$$
M \ddot{q}(t)+C \dot{q}(t)+K q(t)=f(t),
$$

where $M, C$, and $K$ are, respectively, the mass, damping, and stiffness matrices of the whole connected building structures including substructures and connected systems. $f(t)$ is the external force vector.

In equation (1), $q(t)=\left[\left\{q^{(1)}(t)\right\}^{T},\left\{q^{(2)}(t)\right\}^{T}, \ldots\right.$, $\left.\left\{q^{(R)}(t)\right\}^{T}\right]^{T}$ is the overall displacement vector of the connected building structure. Therefore, the mass matrix, damping matrix, and stiffness matrix of the whole connected building structure can be expressed as follows:

$$
\begin{aligned}
M^{(j)} & =\operatorname{diag}\left\{m_{1}^{j}, \ldots, m_{n_{j}}^{j}\right\}, \quad 1 \leq j \leq R, \\
C & =\bar{C}+\widehat{C}, \\
K & =\bar{K}+\widehat{K},
\end{aligned}
$$

where $M^{(j)}=\operatorname{diag}\left[m_{1}^{j}, \ldots, m_{n_{j}}^{j}\right], 1 \leq j \leq R$ are the substructure mass matrices shown in formula (3). Matrices $\bar{C}$ and $\bar{K}$ are, respectively, damping and stiffness matrices of substructures. The matrices have the following block diagonal form: 


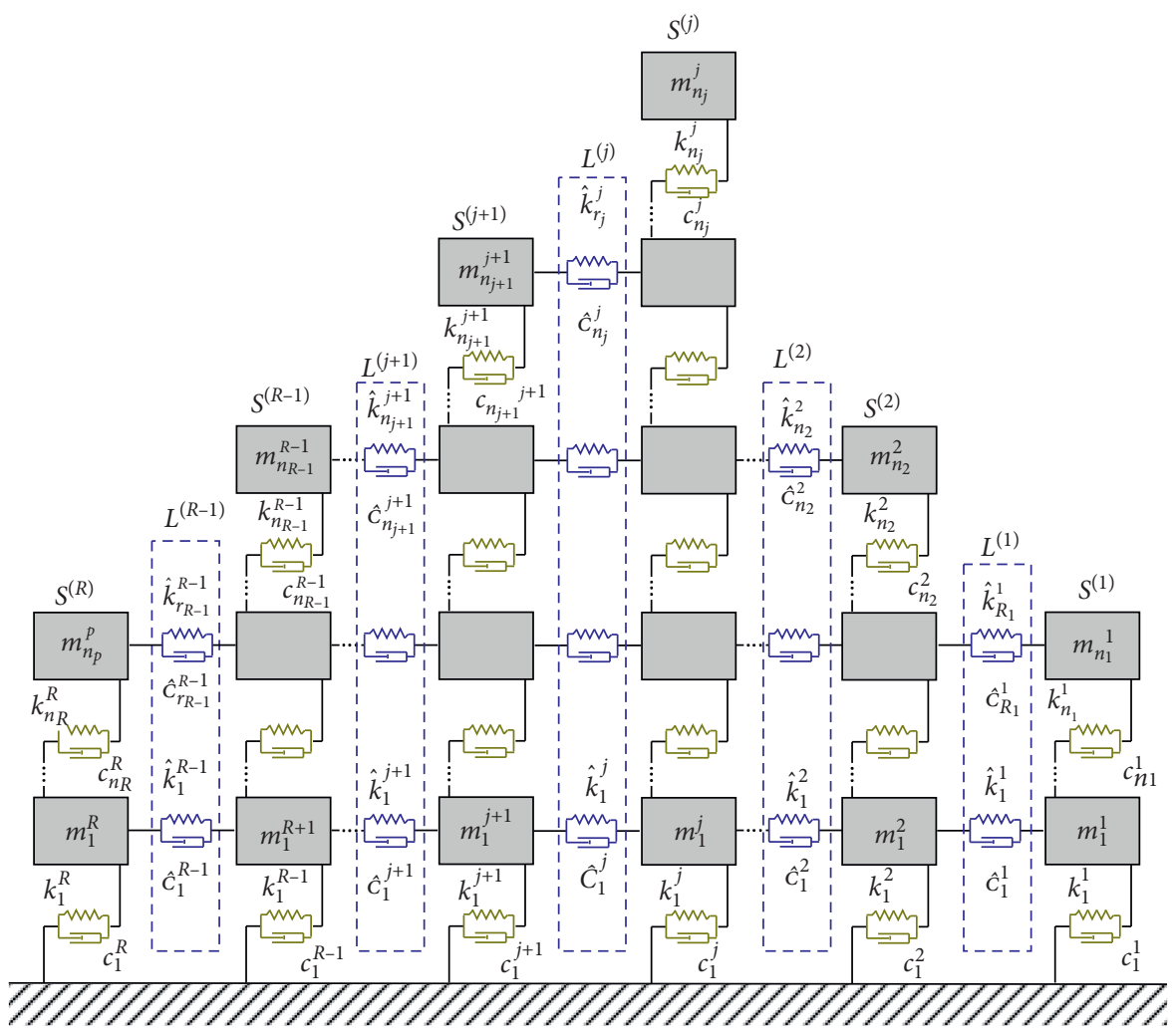

FIgURE 1: Schematic diagram of the adjacent structure connection system.

$$
\begin{aligned}
& \bar{C}=\operatorname{diag}\left\{C^{(1)}, C^{(2)}, \ldots, C^{(R)}\right\}, \\
& \bar{K}=\operatorname{diag}\left\{K^{(1)}, K^{(2)}, \ldots, K^{(R)}\right\},
\end{aligned}
$$

where matrices $C^{(j)}$ and $K^{(j)}$ can be described as the following structural forms:

$$
C^{(j)}=\left[\begin{array}{ccccc}
c_{1}^{j}+c_{2}^{j} & -c_{2}^{j} & & & \\
-c_{2}^{j} & c_{2}^{j}+c_{3}^{j} & -c_{3}^{j} & & \\
& \cdots & \cdots & \cdots & \\
& & -c_{n_{j-1}}^{j} & c_{n_{j-1}}^{j}+c_{n_{j}}^{j} & -c_{n_{j}}^{j} \\
& & & -c_{n_{j}}^{j} & c_{n_{j}}^{j}
\end{array}\right],
$$

where stiffness matrix $K^{(j)}$ has a similar structural form with the damping matrix $C^{(j)}$. The damping and stiffness matrices of connecting system $L^{(j)}$ can be expressed as follows:

$$
\begin{aligned}
\widehat{C}^{(j)} & =\operatorname{diag}\left[\widehat{c}_{1}^{j}, \ldots, \widehat{c}_{r_{j}}^{j}\right], \\
\widehat{K}^{(j)} & =\operatorname{diag}\left[\widehat{k}_{1}^{j}, \ldots, \widehat{k}_{r_{j}}^{j}\right], \\
r_{j} & =\min \left(n_{j}, n_{j+1}\right) .
\end{aligned}
$$

The substructural connected system for stiffness matrix $\widehat{K}$ has the following structure form of a tridiagonal block structure matrix:

$$
\widehat{K}=\left[\begin{array}{cccc}
{\left[\widehat{K}^{(1)}\right]_{n_{1} \times n_{1}}} & -\left[\widehat{K}^{(1)}\right]_{n_{1} \times n_{2}} & & \\
-\left[\widehat{K}^{(1)}\right]_{n_{2} \times n_{1}} & {\left[\widehat{K}^{(1)}\right]_{n_{2} \times n_{2}}+\left[\widehat{K}^{(2)}\right]_{n_{2} \times n_{2}}} & -\left[\widehat{K}^{(2)}\right]_{n_{2} \times n_{3}} & \\
& \ldots & \ldots & \\
& -\left[\widehat{K}^{(R-2)}\right]_{n_{R-1} \times n_{R-2}} & {\left[\widehat{K}^{(R-2)}\right]_{n_{R-1} \times n_{R-1}}+\left[\widehat{K}^{(R-1)}\right]_{n_{R-1} \times n_{R-1}}} & -\left[\widehat{K}^{(R-1)}\right]_{n_{R-1} \times n_{R}} \\
& & -\left[\widehat{K}^{(R-1)}\right]_{n_{R} \times n_{R-1}} & {\left[\widehat{K}^{(R-1)}\right]_{n_{R} \times n_{R}}}
\end{array}\right],
$$


and damping matrix $\widehat{C}$ has a similar matrix structure form to stiffness matrix $\widehat{K}$.

Assuming that some external load acts on the substructure system $S^{(j)}$, its stress state diagram is shown in Figure 2.

In Figure 2, $w(t)$ is the external excitation load. $a_{i}^{j}(i=$ $\left.1,2, \ldots, n_{j}\right)$ are the drive control devices. Therefore, the motion equation of the substructure system $S^{(j)}$ under external load excitation can be expressed as follows:

$$
\begin{aligned}
& M^{(j)} \ddot{q}^{(j)}(t)+C^{(j)} \dot{q}^{(j)}(t)+K^{(j)} q^{(j)}(t)-f_{L}^{(j)}(t) \\
& \quad=f_{u}^{(j)}(t)+f_{w}^{(j)}(t)
\end{aligned}
$$

where $f_{u}^{(j)}(t)$ is the control force vector of substructure system $S^{(j)}$ and $f_{w}^{(j)}(t)$ is the inertial force generated by external load excitation on the structure. According to the control device installed in the substructure $S^{(j)}$ floors, its inertial force matrix can be expressed as follows:

$$
f_{w}^{(j)}(t)=-M^{(j)}[1]_{n_{j} \times 1} w(t) .
$$

For the driver control interlayer driving scheme, the control position matrix $S^{(j)}$ of the substructure can be known. The control position matrix of $S^{(j)}$ is expressed as follows:

$$
T_{u}^{(j)}=\left\{\begin{array}{l}
{\left[T_{u}^{(j)}\right]_{i, i}=1, \quad 1 \leq i \leq n_{j},} \\
{\left[T_{u}^{(j)}\right]_{i, i+1}=-1, \quad 1 \leq i \leq n_{j}-1,} \\
{\left[T_{u}^{(j)}\right]_{i, j}=0, \quad \text { otherwise, }}
\end{array}\right.
$$

given by $u^{(j)}(t)=\left[u_{1}^{j}(t), u_{2}^{j}(t), \ldots, u_{n_{j}}^{j}(t)\right]^{T}$, and the control force vector can be gained by

$$
f_{u}^{(j)}(t)=T_{u}^{(j)} u^{(j)}(t)
$$

\section{Structural Model of Adjacent Buildings}

According to equations (1), (7)-(10), the second-order differential motion equation of adjacent building structure shown in Figure 3 can be obtained by

$$
M \ddot{q}(t)+C \dot{q}(t)+K q(t)=T_{u} u(t)+T_{w} w(t),
$$

in which $M$ is the total mass matrix, $C$ and $K$ are the total damping and total stiffness matrices, respectively, including damping and stiffness of connected system $L, u(t)$ represents the control force exerted by the actuation device $a_{i}^{j}\left(i=1,2, \ldots, n_{l}\right.$ or $n_{r} ; j=l$ or $r$ ) (see Figure 3$)$. The floor displacement relative to the ground can be described as vector, $q(t)=\left[q_{1}^{l}(t), \ldots, q_{n_{l}-1}^{l}(t), q_{n_{l}}^{l}(t), q_{1}^{r}(t), \ldots, q_{n_{r}-1}^{r}(t)\right.$, $\left.q_{n_{r}}^{r}(t)\right]^{T}$; in this formula, $q_{i}^{j}(t)$ is the structural displacement of the $i$-th floor of building structure $j$. For the driving system, a group of interlayer force drivers installed on each floor can be set to control the vibration response of the building structure in Figure 1. In equation (11), $T_{w}$ is the matrix of excitation position and $T_{u}$ is the control position matrix.

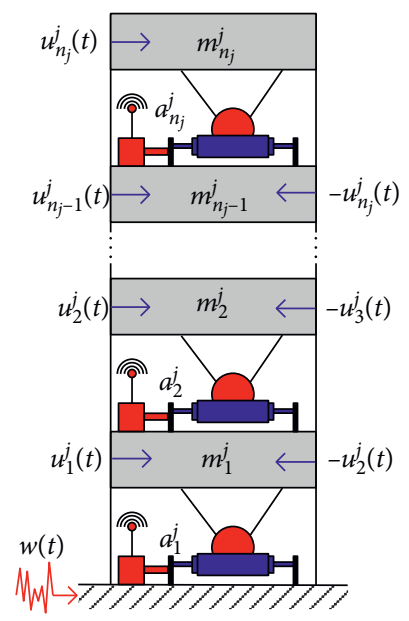

Figure 2: Schematic diagram for external excitations acting upon substructure $S^{(j)}$.

According to Figure 3, the matrix in equation (11) has the following structural form:

$$
M=\left[\begin{array}{cc}
M_{L} & 0 \\
0 & M_{R}
\end{array}\right],
$$

where $M_{L}=\operatorname{diag}\left\{m_{1}^{l}, \ldots, m_{n_{l}-1}^{l}, m_{n_{l}}^{l}\right\}, M_{R}=\operatorname{diag}\left\{m_{1}^{r}, \ldots\right.$, $\left.m_{n_{r}-1}^{r}, m_{n_{r}}^{r}\right\}, C=\bar{C}+\widehat{C}$, and the floor damping matrix can be written by

$$
\bar{C}=\operatorname{diag}\left\{C^{L}, C^{R}\right\}
$$

where

$$
\begin{aligned}
C^{L} & =\left[\begin{array}{ccccc}
c_{1}^{l}+c_{2}^{l} & -c_{2}^{l} & & & \\
-c_{2}^{l} & c_{2}^{l}+c_{3}^{l} & -c_{3}^{l} & & \\
& \ldots & \ldots & \ldots & \\
& & -c_{n_{l}-1}^{l} & c_{n_{l}-1}^{l}+c_{n_{l}}^{l} & -c_{n_{l}}^{l} \\
& & & -c_{n_{l}}^{l} & c_{n_{l}}^{l}
\end{array}\right], \\
C^{R} & =\left[\begin{array}{ccccc}
c_{1}^{r}+c_{2}^{r} & -c_{2}^{r} & & & \\
-c_{2}^{r} & c_{2}^{r}+c_{3}^{r} & -c_{3}^{r} & & \\
& \ldots & \ldots & \ldots & \\
C_{C} & \ldots & & \\
\operatorname{Ciag}\left\{\widehat{c}_{1}, \ldots, \widehat{c}_{n_{l}-1}, \widehat{c}_{n_{l}}\right\} & & & \\
-C_{C} & C_{C} & 0 \\
0 & 0 & 0
\end{array}\right],
\end{aligned}
$$

And $K=\bar{K}+\widehat{K}$, where $K, \bar{K}$, and $\widehat{K}$ matrices have similar structural forms as $C, \bar{C}$, and $\widehat{C}$, respectively.

$$
\bar{K}=\operatorname{diag}\left\{K^{L}, K^{R}\right\} \text {, }
$$

where 


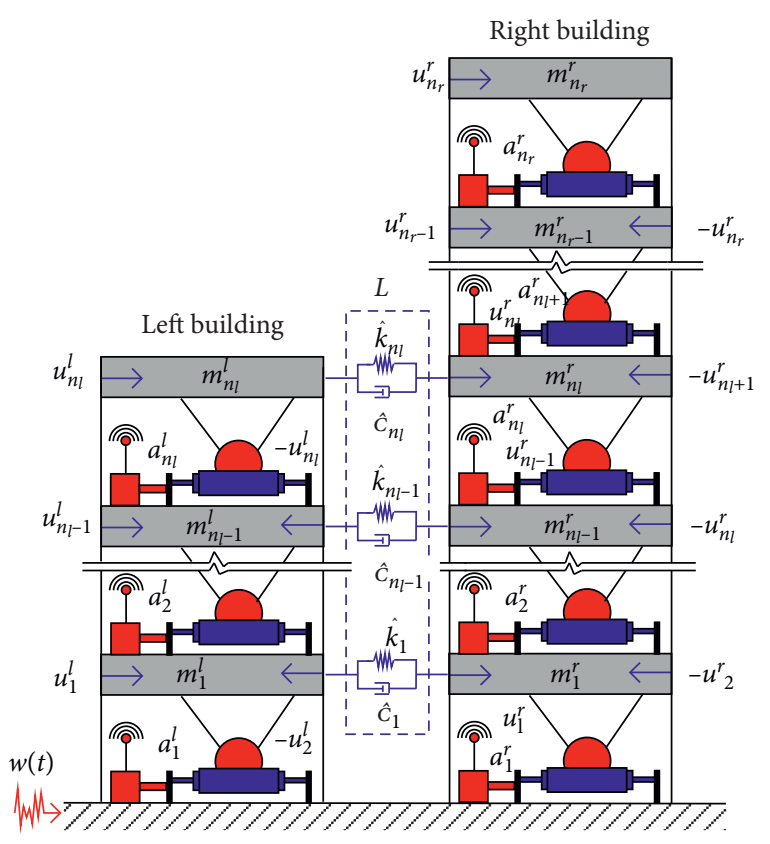

FIgURE 3: Structural model of two adjacent buildings.

$$
\begin{aligned}
& K^{L}=\left[\begin{array}{ccccc}
k_{1}^{l}+k_{2}^{l} & -k_{2}^{l} & & & \\
-k_{2}^{l} & k_{2}^{l}+k_{3}^{l} & -k_{3}^{l} & & \\
& \ldots & \ldots & \ldots & \\
& & -k_{n_{l}-1}^{l} & k_{n_{l}-1}^{l}+k_{n_{l}}^{l} & -k_{n_{l}}^{l} \\
& & & -k_{n_{l}}^{l} & k_{n_{l}}^{l}
\end{array}\right], \\
& K^{R}=\left[\begin{array}{ccccc}
k_{1}^{r}+k_{2}^{r} & -k_{2}^{r} & & & \\
-k_{2}^{r} & k_{2}^{r}+k_{3}^{r} & -k_{3}^{r} & & \\
& \ldots & \ldots & \ldots & \\
& & -k_{n_{r}-1}^{r} & k_{n_{r}-1}^{r}+k_{n_{r}}^{r} & -k_{n_{r}}^{r} \\
& & & -k_{n_{r}}^{r} & k_{n_{r}}^{r}
\end{array}\right], \\
& K_{C}=\left[\begin{array}{ccc}
K_{C} & -K_{C} & 0 \\
-K_{C} & K_{C} & 0 \\
0 & 0 & 0
\end{array}\right], \\
& \operatorname{diag}\left\{\hat{k}_{1}, \ldots, \hat{k}_{n_{l}-1}, \hat{k}_{n_{l}}\right\} .
\end{aligned}
$$

The interlayer driven controller position matrix $T_{u}$ has the following structure form:

$$
\begin{aligned}
T_{u} & =\operatorname{diag}\left\{T_{u}^{l}, T_{u}^{r}\right\}, \\
T_{u}^{l} & =\left\{\begin{array}{l}
{\left[T_{u}^{l}\right]_{i, i}=1, \quad 1 \leq i \leq n_{l},} \\
{\left[T_{u}^{l}\right]_{i, i+1}=-1, \quad 1 \leq i<n_{l}, T_{u}^{r}} \\
{\left[T_{u}^{l}\right]_{i, j}=0, \quad \text { otherwise, }}
\end{array}\right. \\
& =\left\{\begin{array}{l}
{\left[T_{u}^{r}\right]_{i, i}=1, \quad 1 \leq i \leq n_{r},} \\
{\left[T_{u}^{r}\right]_{i, i+1}=-1, \quad 1 \leq i<n_{r},} \\
{\left[T_{u}^{r}\right]_{i, j}=0, \quad \text { otherwise. }}
\end{array}\right.
\end{aligned}
$$

From the second-order model in equation (11), the firstorder spatial state model can be transformed into the following:

$$
S_{I}:\left\{\begin{array}{l}
\dot{x}_{I}(t)=A_{I} x_{I}(t)+B_{I} u(t)+E_{I} w(t), \\
y_{I}(t)=\left[C_{y}\right]_{I} x_{I}(t) .
\end{array}\right.
$$

In the aforementioned matrices,

$$
\begin{aligned}
x_{I}(t) & =\left[\begin{array}{c}
q(t) \\
\dot{q}(t)
\end{array}\right], \\
A_{I} & =\left[\begin{array}{cc}
{[0]\left(n_{l}+n_{r}\right) \times\left(n_{l}+n_{r}\right)} & I_{\left(n_{l}+n_{r}\right)} \\
-M^{-1} K & -M^{-1} C
\end{array}\right], \\
B_{I} & =\left[\begin{array}{c}
0 \\
M^{-1} T_{u}
\end{array}\right], \\
E_{I} & =\left[\begin{array}{c}
{[0] n_{\left(n_{l}+n_{r}\right) \times 1}} \\
-[1]_{\left(n_{l}+n_{r}\right) \times 1}
\end{array}\right] .
\end{aligned}
$$

Since interlayer displacement refers to the relative displacement between adjacent floors of the same buildings, according to literature $[29,30]$, a new first-order state space and a new state vector can be defined as follows:

$$
S:\left\{\begin{array}{l}
\dot{x}(t)=A x(t)+B u(t)+E w(t) \\
y(t)=C_{y} x(t)
\end{array}\right.
$$

in which $C_{y}$ is unit matrix, and a new state vector $x(t)=$ $\left[x_{1}, x_{2}, \ldots, x_{n_{l}+n_{r}}\right]$ can be specifically described as follows:

$$
\left\{\begin{array}{l}
x_{1}(t)=q_{1}^{l}(t), \\
x_{2}(t)=\dot{q}_{1}^{l}(t), \\
x_{2 j-1}(t)=q_{j}^{l}(t)-q_{j-1}^{l}(t), \quad 1<j \leq n_{l}, \\
x_{2 j}(t)=\dot{q}_{j}^{l}(t)-\dot{q}_{j-1}^{l}(t), \quad 1<j \leq n_{l}, \\
x_{n_{l}+1}(t)=q_{1}^{r}(t), \\
x_{n_{l}+2}(t)=\dot{q}_{1}^{r}(t), \\
x_{2 k+n_{l}-1}(t)=q_{k}^{r}(t)-q_{k-1}^{r}(t), \quad 1<k \leq n_{r}, \\
x_{2 k+n_{l}}(t)=\dot{q}_{k}^{r}(t)-\dot{q}_{k-1}^{r}(t), \quad 1<k \leq n_{r} .
\end{array}\right.
$$

\section{Overlapping Decentralized $\mathbf{H}_{\infty}$ Control Design}

4.1. $H_{\infty}$ Control Algorithm. Considering the state system in equation (20) and the control output $z(t)=C_{z} x(t)+$ $D_{z} u(t)$, the following linear time-invariant system equation can be obtained [31]:

$$
S_{S}:\left\{\begin{array}{l}
\dot{x}(t)=A x(t)+B u(t)+E w(t), \\
y(t)=C_{y} x(t), \\
z(t)=C_{z} x(t)+D_{z} u(t) .
\end{array}\right.
$$


For a given state feedback controller $u(t)=G y(t)$, the system $S_{S}$ in equation (22) can be transformed into the following closed-loop system:

$$
S_{\mathrm{CL}}:\left\{\begin{array}{l}
\dot{x}(t)=\left[A+B G C_{y}\right] x(t)+E w(t), \\
z(t)=\left[C_{z}+D_{z} G C_{y}\right] x(t) .
\end{array}\right.
$$

The closed-loop transfer function from the perturbation matrix $w(t)$ to the control output matrix $z(t)$ is expressed as follows:

$$
T_{z w}(s)=\left(C_{z}+D_{z} G C_{y}\right)\left[s I-\left(A+B G C_{y}\right)\right]^{-1} E .
$$

In $\mathrm{H}_{\infty}$ control design, the goal is to find a control matrix $G$ that minimizes $\gamma_{G}$ as follows:

$$
\gamma_{G}=\left\|T_{z w}(s)\right\|_{\infty}=\max _{\omega} \bar{\sigma}\left[T_{z w}(2 \pi \omega j)\right],
$$

in which $s=\omega j, j=\sqrt{-1}, \omega$ is the frequency in hertz, and $\bar{\sigma}[\cdot]$ is the largest singular value.

Theorem 1. Consider the linear continuous time system $S_{C L}$ in equation (23), for the certain scalar $\gamma>0$, based on the bounded real lemma assuming that the matrix $Y$ and $P>0$ satisfy the linear matrix inequality (LMI) as follows:

$$
\left[\begin{array}{cc}
A P+P A^{T}+B Y+[B Y]^{T}+\gamma^{-2} E E^{T} & * \\
C_{z} P+D_{z} Y & -I
\end{array}\right]<0,
$$

$$
\begin{aligned}
J \leq & \int_{0}^{\infty}\left[z^{T}(t) z(t)-\gamma^{2} w^{T}(t) w(t)+\dot{V}(x, t)\right] \mathrm{d} t \\
= & \int_{0}^{\infty} z^{T}(t) z(t) \mathrm{d} t-\int_{0}^{\infty} \gamma^{2} w^{T}(t) w(t) \mathrm{d} t+\int_{0}^{\infty} \dot{V}(x, t) \mathrm{d} t \\
= & \int_{0}^{\infty} x^{T}(t)\left\{\left[C_{z}+D_{z} G C_{y}\right]^{T}\left[C_{z}+D_{z} G C_{y}\right]\right\} x(t) \mathrm{d} t-\int_{0}^{\infty} \gamma^{2} w^{T}(t) w(t) \mathrm{d} t \\
& +\int_{0}^{\infty} x^{T}(t)\left[W\left[A+B G C_{y}\right]+\left[A+B G C_{y}\right]^{T} W\right] x(t) \mathrm{d} t+\int_{0}^{\infty} 2 x^{T}(t) W E w(t) \mathrm{d} t \\
= & \int_{0}^{\infty} x(t)\left[W\left[A+B G C_{y}\right]+\left[A+B G C_{y}\right]^{T} W\right] x(t) \mathrm{d} t+\int_{0}^{\infty} x^{T}(t)\left\{\left[C_{z}+D_{z} G C_{y}\right]^{T}\left[C_{z}+D_{z} G C_{y}\right]\right\} x(t) \mathrm{d} t \\
& +\int_{0}^{\infty}\left[2 x^{T}(t) W E w(t)-\gamma^{2} w^{T}(t) w(t)\right] \mathrm{d} t .
\end{aligned}
$$

Since the following inequitable relations exist,

$$
2 x^{T}(t) W E w(t) \leq \gamma^{-2} x^{T}(t) W E E^{T} W x(t)+\gamma^{2} w^{T}(t) w(t)
$$

$$
2 x^{T}(t) W E w(t)-\gamma^{2} w^{T}(t) w(t) \leq \gamma^{-2} x^{T}(t) W E E^{T} W x(t) .
$$

Thus, by substituting equations (31) and (32) into equation (30), it can be obtained by where * shows symmetry, $P$ is a symmetric positive definite matrix, given by $Y=G P$, and output feedback controller $u(t)=G y(t)$ made with $H_{\infty}$ bounded norm $\gamma$ in equation (23) of the closed-loop system is asymptotically stable.

Proof. The proof of Theorem 1 is given as follows.

In a closed-loop system in equation (23), for $w(t) \neq 0$, $w(t) \in L_{2}^{p}[0, \infty)$, the following inequality is available:

$$
J \leq \int_{0}^{\infty}\left[z^{T}(t) z(t)-\gamma^{2} w^{T}(t) w(t)+\dot{V}(x, t)\right] \mathrm{d} t .
$$

According to the Lyapunov principle, the Lyapunov function is properly constructed. Now, suppose there is a Lyapunov function related to time $t$ as follows:

$$
V(x, t)=x^{T}(t) W x(t) .
$$

The first derivative of the time $t$ in equation (28) now can be obtained by

$$
\begin{aligned}
\dot{V}(x, t) & =\dot{x}^{T}(t) W x(t)+x^{T}(t) W \dot{x}(t) \\
& =x^{T}(t)\left[W\left[A+B G C_{y}\right]+\left[A+B G C_{y}\right]^{T} W\right] x(t) \\
& +2 x^{T}(t) W E w(t) .
\end{aligned}
$$

Then, by substituting equation (29) into equation (27), the following inequality can be expressed: 
The aforementioned inequality can be described as follows:

$$
\begin{aligned}
& W A+A^{T} W+\gamma^{-2} W E E^{T} W+\left[W B G C_{y}\right]+\left[W B G C_{y}\right]^{T} \\
& +\left[C_{z}+D_{z} G C_{y}\right]^{T}\left[C_{z}+D_{z} G C_{y}\right]<0 .
\end{aligned}
$$

Since that $W$ is a symmetric positive definite matrix, also is $W>0$, there is $\left[W B G C_{y}\right]^{T}=\left[B G C_{y}\right]^{T} W$, so equation (34) can be expressed as follows:

$$
\begin{gathered}
A W^{-1}+W^{-1} A^{T}+\gamma^{-2} E E^{T}+\left[B G C_{y} W^{-1}\right]+W^{-1}\left[B G C_{y}\right]^{T} \\
+W^{-1}\left[C_{z}+D_{z} G C_{y}\right]^{T}\left[C_{z}+D_{z} G C_{y}\right] W^{-1}<0 .
\end{gathered}
$$

In addition, since there are $W^{-1}\left[B G C_{y}\right]^{T}=\left[W^{-1}\right]^{T}$ $\left[B G C_{y}\right]^{T}=\left[B G C_{y} W^{-1}\right]^{T}$ and $W^{-1}\left[C_{z}+D_{z} G C_{y}\right]^{T}=\left[\left[C_{z}+\right.\right.$ $\left.\left.D_{z} G C_{y}\right] W^{-1}\right]^{T}$, equation (35) can be obtained by

$$
\begin{gathered}
A W^{-1}+W^{-1} A^{T}+\gamma^{-2} E E^{T}+\left[B G C_{y} W^{-1}\right]+\left[B G C_{y} W^{-1}\right]^{T} \\
+\left[C_{z} W^{-1}+D_{z} G C_{y} W^{-1}\right]^{T}\left[C_{z} W^{-1}+D_{z} G C_{y} W^{-1}\right]<0 .
\end{gathered}
$$

Now, consider the equivalence relations exist, $P=W^{-1}$ and $Y=G C_{y} P=G C_{y} W^{-1}$, so the above one can be expressed as follows:

$$
\begin{aligned}
A P & +P A^{T}+\gamma^{-2} E E^{T}+[B Y]+[B Y]^{T} \\
& +\left[C_{z} X+D_{z} Y\right]^{T}\left[C_{z} X+D_{z} Y\right]<0 .
\end{aligned}
$$

According to Schur complement lemma, equation (37) can be expressed as follows:

$$
\left[\begin{array}{cc}
A P+P A^{T}+\gamma^{-2} E E^{T}+[B Y]+[B Y]^{T} & * \\
C_{z} P+D_{z} Y & -I
\end{array}\right]<0 .
$$

Therefore, the continuous time Ho control problem can be transformed into the following convex optimization problem:

$$
\left\{\begin{array}{l}
\text { Minimize } \gamma, \\
\text { s.t. the LMI in equation (26), }
\end{array}\right.
$$

where matrices $Y$ and $P$ are optimization variables. If the optimization value $\gamma$ is certain, the corresponding optimization variables are $Y_{\text {op }}$ and $P_{\mathrm{op}}$, and the corresponding gain matrix can be calculated as $G_{\mathrm{op}}=Y_{\mathrm{op}} P_{\mathrm{op}}^{-1}$.

4.2. Overlapped Decentralized $H_{\infty}$ Control Algorithm. The steps of the overlapped decentralized $H_{\infty}$ control algorithm are described as follows:

(1) Considering the stiffness and damping of the connected system $L$, the entire building structure vibration control system can be extended and decoupled into multiple overlapping subsystems. For the linear system $S_{S}$ in equation (22), design the overlapping controller in which the expansion matrix is selected and the corresponding pseudo-inverse contraction matrix is set, and the connecting blocks are removed. The whole structural vibration control system of the building can be extended into $T$ overlapping subsystems $[32,33]$ :

$\widetilde{S}_{D}^{(i)}:\left\{\begin{array}{l}\dot{\tilde{x}}_{i}(t)=\widetilde{A}_{i i} \widetilde{x}_{i}(t)+\widetilde{B}_{i i} \widetilde{u}_{i}(t), \\ \widetilde{y}_{i}(t)=\left(\widetilde{C}_{y}\right)_{i i} \widetilde{x}_{i}(t), \quad i=1,2, \ldots, T .\end{array}\right.$

An extended decoupled subsystem can be defined as follows:

$$
\widetilde{S}_{D}:\left\{\begin{array}{l}
\dot{\tilde{x}}(t)=\widetilde{A}_{D} \widetilde{x}(t)+\widetilde{B}_{D} \widetilde{u}(t), \\
\tilde{y}(t)=\left(\widetilde{C}_{y}\right)_{D} \widetilde{x}(t),
\end{array}\right.
$$

where $\widetilde{A}_{D}=\operatorname{diag}\left\{\widetilde{A}_{11}, \widetilde{A}_{22}, \ldots, \widetilde{A}_{T T}\right\}, \widetilde{B}_{D}=\operatorname{diag}\left\{\widetilde{B}_{11}\right.$, $\left.\widetilde{B}_{22}, \ldots, \widetilde{B}_{T T}\right\}$, and $\left(\widetilde{C}_{y}\right)_{D}=\operatorname{diag}\left\{\left(\widetilde{C}_{y}\right)_{11},\left(\widetilde{C}_{y}\right)_{22}, \ldots\right.$, $\left.\left(\widetilde{C}_{y}\right)_{T T}\right\}$.

(2) For the $\widetilde{S}_{D}^{(i)},(i=1,2, \ldots, T)$ subsystems in equation (40), the $\mathrm{H}_{\infty}$ control algorithm in Section 4.1 can be used to calculate the feedback gain matrices of each subsystem $\widetilde{G}_{(i)},(i=1,2, \ldots, T)$.

(3) Form the diagonal extended feedback gain matrix of the vibration control system of the entire building structure as follows:

$$
\widetilde{G}_{D}=\operatorname{diag}\left\{\widetilde{G}_{(1)}, \widetilde{G}_{(2)}, \ldots, \widetilde{G}_{(T)}\right\} .
$$

According to the contraction principle and linear transformation [32], the extended controller $\widetilde{G}_{D}$ is shrunk into an overlapping controller as follows:

$$
G_{o}=Q \widetilde{G}_{D} V,
$$

where $Q$ and $V$ are, respectively, the contraction and expansion matrices.

\section{Controller Design and Numerical Simulation}

In order to compare the control effects under different decentralized control strategies, this paper selects the adjacent building structure in literature [23] as the design example. Its relevant parameters are as follows: $m_{i}^{j}=1.29 \times$ $10^{6} \mathrm{~kg}, \quad c_{i}^{j}=1.0 \times 10^{5} \mathrm{Ns} / \mathrm{m}, k_{i}^{l}=2.0 \times 10^{9} \mathrm{~N} / \mathrm{m}, k_{i}^{r}=2.4 \times$ $10^{9} \mathrm{~N} / \mathrm{m}, \widehat{c}_{i}=3.0 \times 10^{6} \mathrm{Ns} / \mathrm{m}, \widehat{k}_{i}=0 \mathrm{~N} / \mathrm{m}, 1 \leq i \leq n_{j}, j=l$ or $j=r, n_{l}=3$, and $n_{r}=5$. El Centro (N-S, 1940) wave was selected for seismic excitation which simulates the satisfying case, and the sampling step was $0.02 \mathrm{~S}$. The acceleration time history of seismic wave is shown in Figure 4. Based on the principle of wavelet transform, the energy distribution diagram of the input time history on the natural frequencytime plane is obtained in Figure 5. The maximum absolute interlaminar displacement and maximum absolute control force are calculated and compared by seismic wave. Three kinds of control methods based on linear matrix inequality can be designed which are as follows: (1) centralized control 


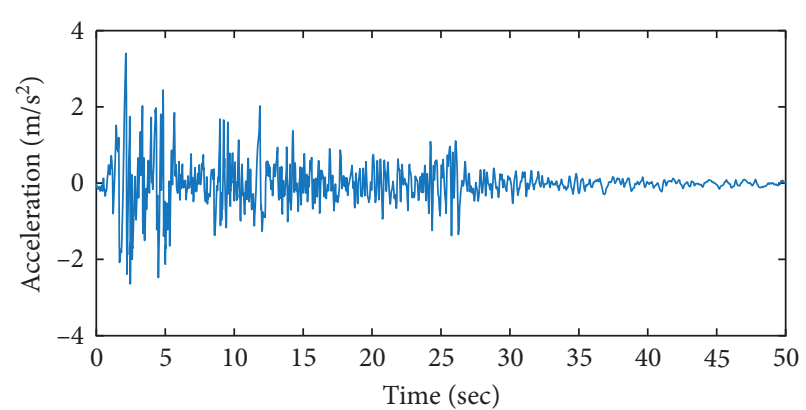

Figure 4: El Centro (1940) earthquake N-S component of ground motion acceleration time histories.

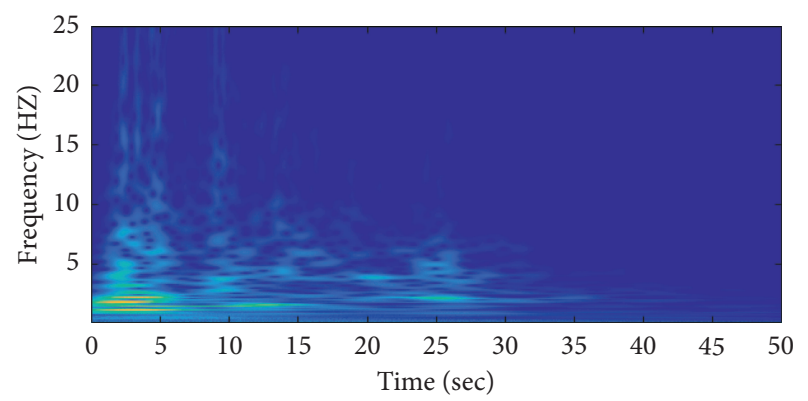

Figure 5: The wavelet-based energy distribution of input time history on natural frequency-time plane.

method; (2) decentralized control method; and (3) overlapping decentralized control method.
5.1. Centralized Control. The centralized control adopts the $H_{\infty}$ control algorithm in Section 4.1 to control the vibration control system of the whole adjacent building structure. To calculate the centralized control gain matrix, the matrix parameters in the closed-loop system $S_{\mathrm{CL}}$ in equation (23) can be set as follows:

$$
\begin{aligned}
& C_{z}=\left[\begin{array}{c}
C_{y} \\
0_{8 \times 16}
\end{array}\right], \\
& D_{z}=0.3461 \times 10^{-7}\left[\begin{array}{c}
0_{8 \times 8} \\
I_{8 \times 8}
\end{array}\right], \\
& C_{y}=\left\{\begin{array}{l}
{\left[C_{y}\right]_{i, 2 i-1}=1, \quad 1 \leq i \leq 8,} \\
{\left[C_{y}\right]_{i+1,2 i-1}=-1, \quad 1 \leq i \leq 8,} \\
{\left[C_{y}\right]_{i, j}=0, \quad \text { otherwise. }}
\end{array}\right.
\end{aligned}
$$

The inequality problem in equation (39) can be solved according to the parameters above, and the $H_{\infty}$ norm centralized control feedback gain matrix $G_{c}$ can be obtained as follows:

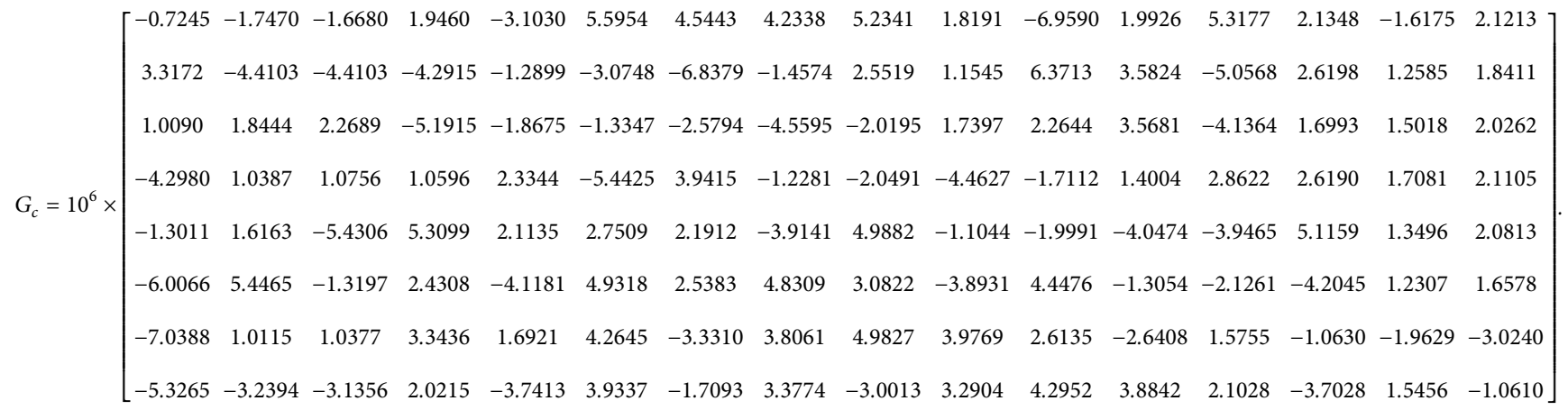

5.2. Decentralized Control. In this section, a block diagonal structure matrix is applied in the control gain matrix to realize the decentralized control of the whole adjacent building structural coupling system. In order to solve the problem of inequality problem in equation (39), the following forms of inequality variables are set [34-36]:

$$
\begin{aligned}
& P=\left[\begin{array}{cc}
P_{11} & 0 \\
0 & P_{22}
\end{array}\right], \\
& Y=\left[\begin{array}{cc}
Y_{11} & 0 \\
0 & Y_{22}
\end{array}\right],
\end{aligned}
$$

where $P_{11}$ and $P_{22}$ are $6 \times 6$ and $10 \times 10$ dimensional positive definite matrices, respectively, and $Y_{11}$ and $Y_{22}$ are $3 \times 6$ and $5 \times 10$ dimensional rectangular matrices, respectively. The settings of $C_{z}$ and $D_{z}$ matrices parameters in control output $z(t)=C_{z} x(t)+D_{z} u(t)$ are same as those in Section 5.1. $P_{11}$, $P_{22}, Y_{11}$, and $Y_{22}$ in formula (46) should be set in advance when solving the vibration control system of building structure. After solving the corresponding constrained minimization problem of the linear matrix inequality (LMI) and on the basis of control gain matrix calculation formula $G_{d}=Y P^{-1}$, corresponding block diagonal gain matrix of the structure vibration control system can obtained by 


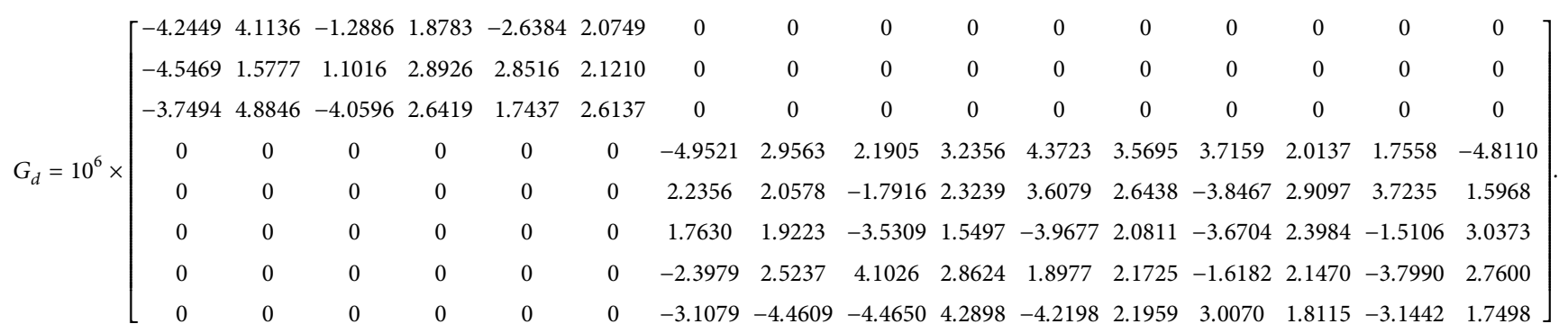

5.3. Overlapping Decentralized Control. According to equation (40), the entire vibration control system of the building structure is overlapping and decomposed into 9 subsystems in Figure 6.

As shown in Figure 6, the information of each floor is shared by neighboring floors (including upper and lower adjacent floors and left and right adjacent floors). According to the overlapping decentralized $\mathrm{H}_{\infty}$ control algorithm of the subsystems which is presented in step (1) in Section 4.2 and corresponding solving inequality problem in equation (39), the extended decoupling of each subsystem can be set to control the output $z(t)=C_{z} x(t)+D_{z} u(t)$, in which the parameters of $C_{z}$ and $D_{z}$ matrices are expressed as follows:

$$
\begin{aligned}
C_{z} & =\left[\begin{array}{c}
C_{y} \\
0_{2 \times 4}
\end{array}\right], \\
D_{z} & =0.3461 \times 10^{-7}\left[\begin{array}{c}
0_{2 \times 2} \\
I_{2 \times 2}
\end{array}\right],
\end{aligned}
$$

$$
C_{y}=\left\{\begin{array}{l}
{\left[C_{y}\right]_{i, 2 i-1}=1, \quad 1 \leq i \leq 2,} \\
{\left[C_{y}\right]_{i+1,2 i-1}=-1, \quad 1 \leq i \leq 2,} \\
{\left[C_{y}\right]_{i, j}=0, \quad \text { otherwise. }}
\end{array}\right.
$$

Therefore, the feedback gain matrix of each subsystem can be calculated by $\widetilde{G}_{(i)},(i=1,2, \ldots, 9)$ and $\widetilde{G}_{(i)}$ is the feedback gain matrix of the $i$-th subsystem $S_{i}$. From formula (42), the diagonally extended feedback gain matrix $\widetilde{G}_{D}=$ $\operatorname{diag}\left[\widetilde{G}_{(1)}, \widetilde{G}_{(2)}, \ldots, \widetilde{G}_{(9)}\right]$ can be obtained, and according to references $[37,38]$, the following parameters can be set:

$$
\begin{aligned}
& Q=\operatorname{diag}\left(0.5\left[I_{1}, I_{1}\right], \frac{1}{3}\left[I_{1}, I_{1}, I_{1}\right], 0.5\left[I_{1}, I_{1}\right], 0.5\left[I_{1}, I_{1}\right], \frac{1}{3}\left[I_{1}, I_{1}, I_{1}\right], \frac{1}{3}\left[I_{1}, I_{1}, I_{1}\right], 0.5\left[I_{1}, I_{1}\right], I_{1}\right), \\
& V=\operatorname{diag}\left(\left[\begin{array}{c}
I_{2} \\
I_{2}
\end{array}\right],\left[\begin{array}{l}
I_{2} \\
I_{2} \\
I_{2}
\end{array}\right],\left[\begin{array}{c}
I_{2} \\
I_{2}
\end{array}\right],\left[\begin{array}{c}
I_{2} \\
I_{2}
\end{array}\right],\left[\begin{array}{l}
I_{2} \\
I_{2} \\
I_{2}
\end{array}\right],\left[\begin{array}{c}
I_{2} \\
I_{2} \\
I_{2}
\end{array}\right],\left[\begin{array}{c}
I_{2} \\
I_{2}
\end{array}\right], I_{2}\right) .
\end{aligned}
$$

The overlapping decentralized control feedback gain matrix $G_{\text {od }}=Q \widetilde{G}_{D} V$ can be obtained from formulas (39) and (43) as follows:

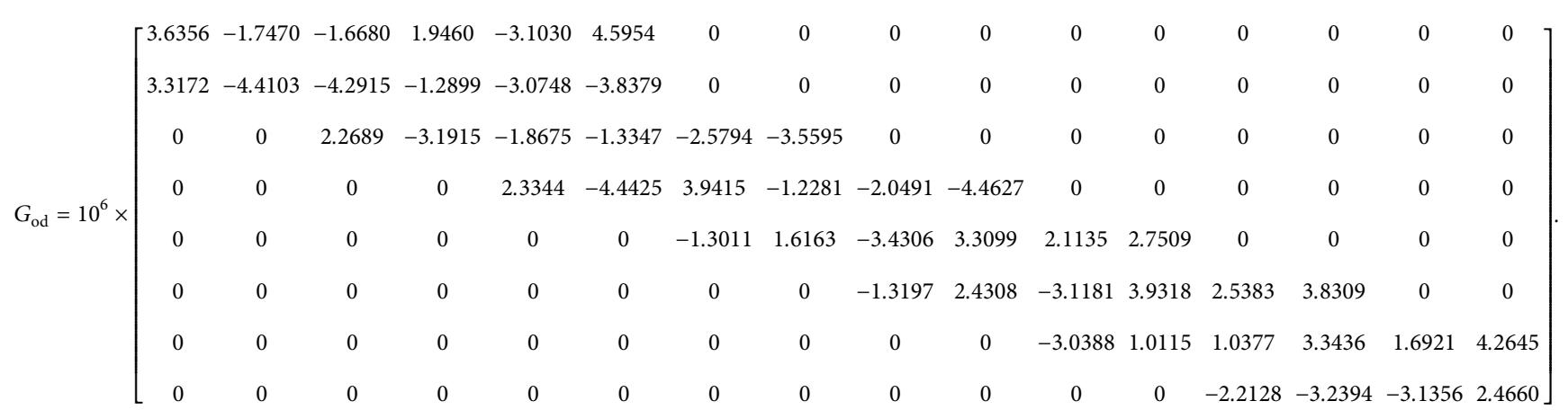




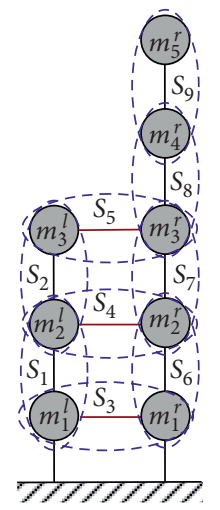

FIgURE 6: Schematic diagram of nine-subsystem overlapping controller design.

5.4. Controller Signals and Seismic Response Results. Based on the feedback gain matrix and equation (25) under different control strategies, the maximum signal value of the controller calculated is shown in Figure 7.

According to Figure 7, the associated minimum $\gamma$ value of the $H_{\infty}$ centralized control is $\left\|T_{z w}\left(G_{c}\right)\right\|_{\infty}=\gamma_{G_{c}}=0.135$, the corresponding minimum $\gamma$ value of the $H_{\infty}^{c}$ decentralized control is $\left\|T_{z w}\left(G_{G_{d}}\right)\right\|_{\infty}=\gamma_{G_{d}}=0.181$, and corresponding the minimum $\gamma$ value of the $H_{\infty}$ overlapping decentralized control is $\left\|T_{z w}\left(G_{G_{\text {od }}}\right)\right\|_{\infty}=\gamma_{G_{\text {od }}}=0.206$.

Remark 1. As the degree of decentralization increases, the maximum singular values become larger. In this paper, the corresponding controller gain matrix is designed according to different control strategies, taking $\gamma$ value as reference value. However, in the actual engineering structure vibration control, the design of the controller can be calculated independently based on the frequency and time response of the building structure itself.

The maximum interlayer displacement and shock absorption rate of adjacent building structures are shown in Table 1. The maximum interlayer displacement and maximum control force of the building structure on the left are shown in Figure 8. The maximum interlayer displacement and maximum control force of the building structure on the right are shown in Figure 9.

Remark 2. It can be seen from Table 1 that in the left structure of adjacent buildings, the control rate of the centralized control strategy ranged from $47.04 \%$ to $61.58 \%$. The decentralized one is between $41.03 \%$ and $53.65 \%$, and the overlapping decentralized one is between $37.53 \%$ and $53.64 \%$. While in the right structure of adjacent buildings, the control rate of centralized control strategy is between $25.78 \%$ and $59.35 \%$. The decentralized one ranged from $24.12 \%$ to $53.22 \%$, and the overlapping decentralized one ranged from $17.09 \%$ to $44.90 \%$. Therefore, in the vibration control strategy of adjacent buildings, the control effect of the centralized control strategy is generally better than that of the decentralized control strategy and the overlapping decentralized control strategy.
Remark 3. When calculated by the Matlab program, the runtime of the centralized control strategy is 2 hours, the runtime of the decentralized one is 30 minutes, yet the runtime of the overlapping decentralized one is 40 seconds. Thus, we can learn that the decentralized control strategy and the overlapping decentralized control strategy reduce both the computing cost. Because the overlapping decentralized control can be independently designed according to the number of degrees of freedom of the building structure, the design of the controller has more features in flexibility.

Remark 4. All calculations in this article were performed using Matlab ${ }^{\circledR} \mathrm{R} 2016 \mathrm{~b}$ on a laptop equipped with a $2.30 \mathrm{GHz}$ Intel (R) Core (TM) i5-6200U processor. The LMI optimization problems corresponding to different controller designs are solved by the function program mincx ( ) included in the Robust Control Toolbox ${ }^{\mathrm{TM}}$.

Figures 8(a) and 9(a) summarize the building interlayer displacements of four different configurations: (1) no control of the coupling system in the uncontrolled state; (2) $H_{\infty}$ norm centralized control response peak (centralized) for the coupled system; (3) $H_{\infty}$ norm decentralized control response peak (decentralized) of coupling system; and (4) overlapping decentralized $\mathrm{H}_{\infty}$ norm control response peak (Overlap.Decent.) of the coupling system. According to the maximum interlayer displacements in Table 1. In Figures 8(b) and 9(b), it can be seen that the control effect of centralized control is optionally best, while the control effect of decentralized control and overlapping decentralized control is slightly worse than that of centralized control, but it can also achieve good control effect.

\section{Conclusions}

(1) With the development of civil structures in the direction of the large span and multidegree of freedom, traditional seismic isolation technology is needed to be reformed to resist the external forces and attenuating excessive amplitudes of oscillations, which prevents from danger and financial lost caused by seismic excitation. The motion state equation of multiadjacent building structures under seismic excitation has been deduced in this paper. 


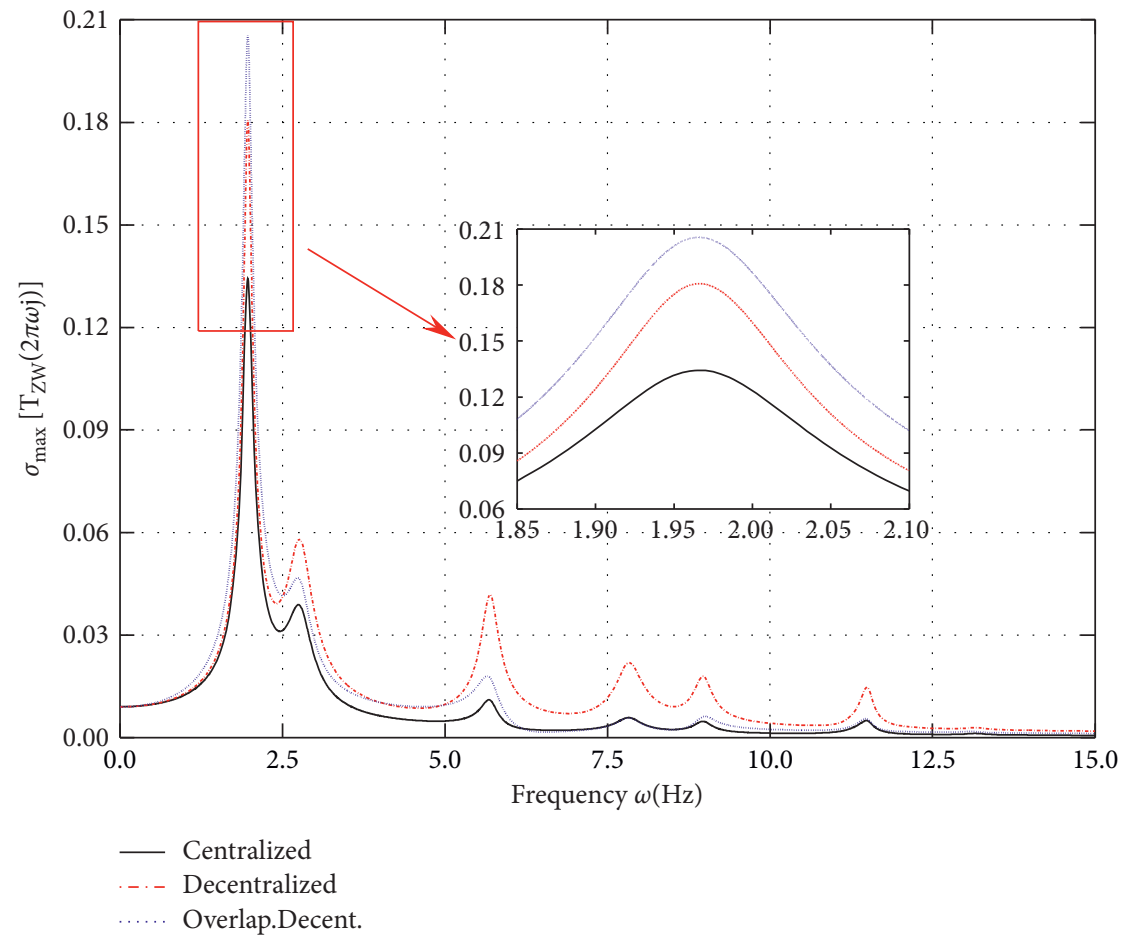

Figure 7: Maximum singular values.

TABLE 1: The maximum interlayer displacement and shock absorption rate of the adjacent building structures.

The maximum interlayer displacement of the left building The maximum interlayer displacement of the right building structure

\begin{tabular}{|c|c|c|c|c|c|c|c|c|}
\hline \multirow[b]{2}{*}{ Stories } & \multirow[b]{2}{*}{$\begin{array}{l}\text { No control } \\
\quad(\mathrm{cm})\end{array}$} & & \\
\hline & & $\begin{array}{c}\text { Centralized } \\
\text { control }(\mathrm{cm} \\
(\%))\end{array}$ & $\begin{array}{l}\text { Decentralized } \\
\text { control }(\mathrm{cm} \\
(\%))\end{array}$ & $\begin{array}{c}\text { Overlapping } \\
\text { decentralized } \\
\text { control }(\mathrm{cm}(\%))\end{array}$ & $\begin{array}{c}\text { No } \\
\text { control } \\
(\mathrm{cm})\end{array}$ & $\begin{array}{c}\text { Centralized } \\
\text { control }(\mathrm{cm} \\
(\%))\end{array}$ & $\begin{array}{l}\text { Decentralized } \\
\text { control }(\mathrm{cm} \\
(\%))\end{array}$ & $\begin{array}{c}\text { Overlapping } \\
\text { decentralized } \\
\text { control }(\mathrm{cm}(\%))\end{array}$ \\
\hline 1 & 1.8756 & $0.7421(60.43)$ & $0.8900(52.54)$ & $0.9415(49.80)$ & 1.8063 & $0.7342(59.35)$ & $0.9497(47.42)$ & $1.0732(40.58)$ \\
\hline 2 & 1.8103 & $0.6954(61.58)$ & $0.8390(53.65)$ & $0.8392(53.64)$ & 1.5390 & $0.6315(58.96)$ & $0.7198(53.22)$ & $0.9718(36.85)$ \\
\hline 3 & 1.1524 & $0.6102(47.04)$ & 0.6795 & $0.7198(37.53)$ & 1.4710 & $0.6338(56.91)$ & $0.7131(51.52)$ & $0.8104(44.90)$ \\
\hline 4 & - & - & - & - & 1.1502 & $0.4722(58.94)$ & $0.6521(43.30)$ & $0.6946(39.61)$ \\
\hline 5 & - & - & - & - & 0.6214 & $0.4612(25.78)$ & $0.4715(24.12)$ & $0.5152(17.09)$ \\
\hline
\end{tabular}

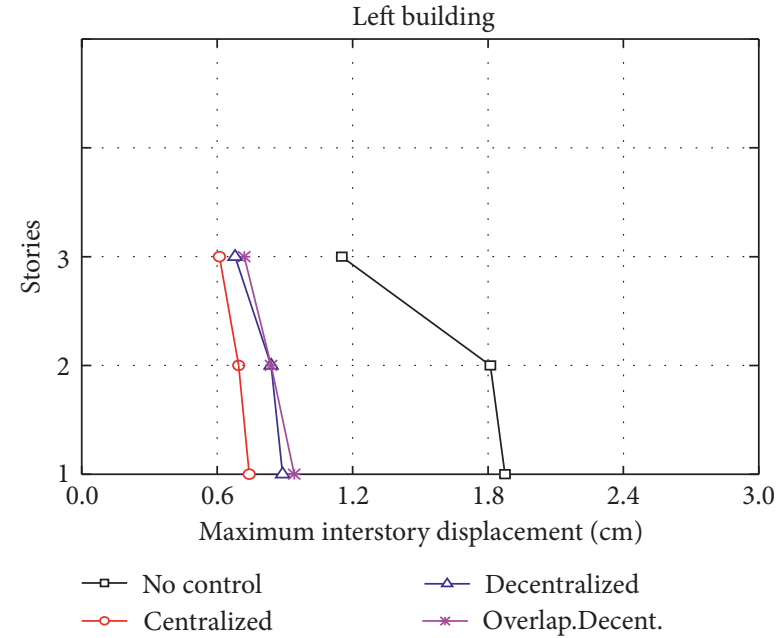

(a)

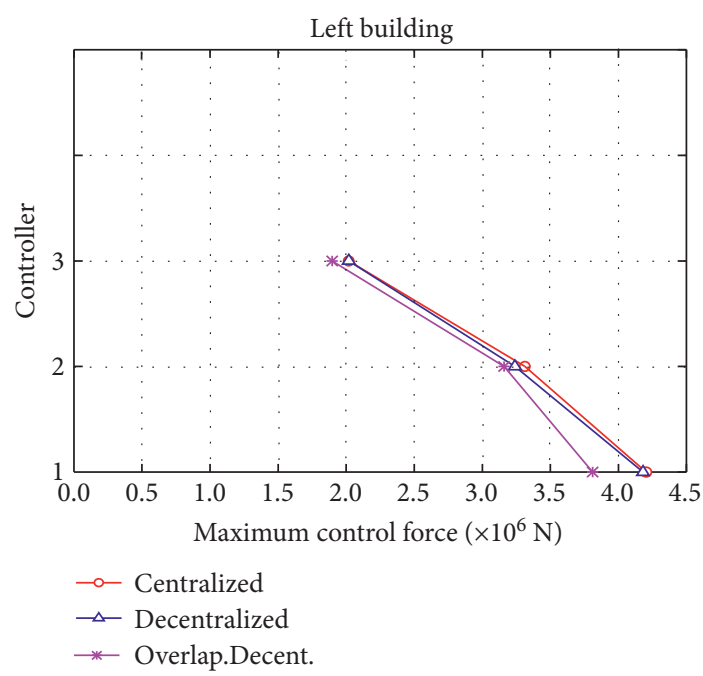

(b)

FIGURE 8: Left building interlayer (a) displacements and (b) control forces. 


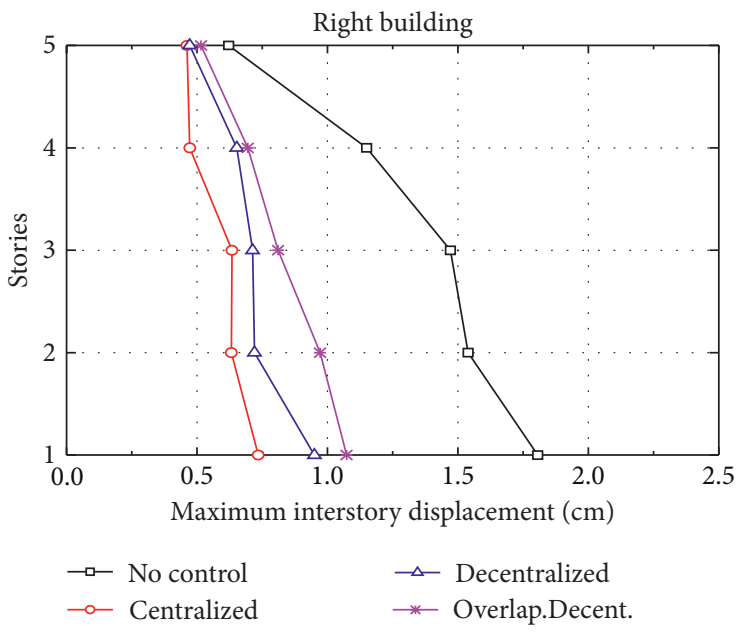

(a)

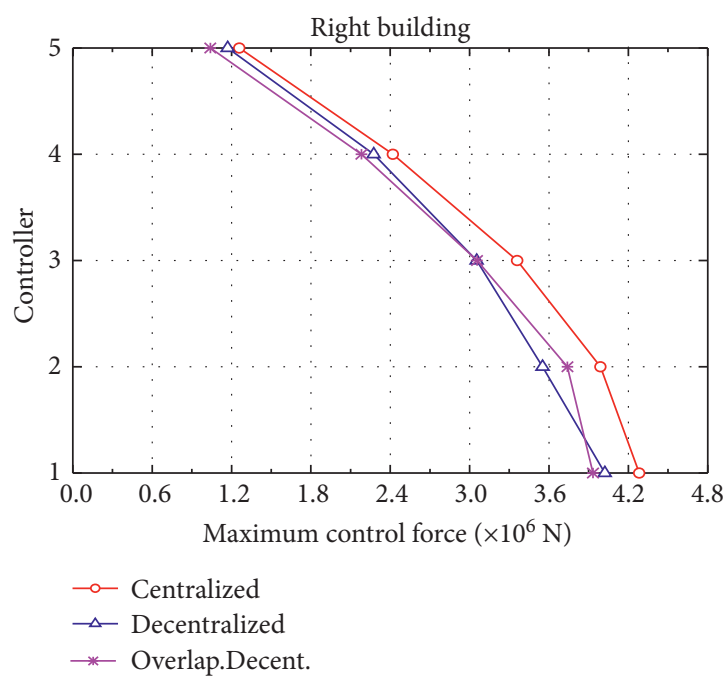

(b)

Figure 9: Right building interlayer (a) displacements and (b) control forces.

(2) In this paper, an overlapping decentralized $H_{\infty}$ norm control method, which is proposed for the vibration control of an adjacent building model, is a competitive optimization. It is also turned out to be relatively stable which can be applied for the practical design of control devices for adjacent building structures demonstrated by numerical statistics. Besides, three kinds of control methods which have desirable control effects based on linear matrix inequality (LMI) are proposed, and the following three examples are given: (1) $H_{\infty}$ norm centralized control method; (2) $H_{\infty}$ norm decentralized control method; and (3) overlapping decentralized $H_{\infty}$ norm control method. These numerical examples can illustrate the rationality of the overlapping decentralized $\mathrm{H}_{\infty}$ norm control method when it is applied to decentralized control of adjacent building structures vibration.

(3) Decentralized control strategies can effectively reduce the vibration response of substructures demonstrated by numerical statistics while overlapping decentralized control strategy provides a new methodology for vibration control of adjacent buildings. Matlab program is used to solve the equations of motion and linear matrix inequality in this paper; therefore, the displacement response reduction in flexibility is achievable.

(4) Compared with the centralized control strategy, the design process of decentralized control strategy and overlapping decentralized control strategy requires specifically shorter calculation time. For the complex control systems, decentralized control strategy contributes to solve the difficulties encountered in controller design, such as parameter uncertainty, sensor and actuator failures, and communication delays. In this case, decentralized design strategies constitute a promising research direction which provide computationally efficient solutions to such complex problems

(5) As the degree of freedom of the structural vibration control system increases, the decentralized control strategy and the overlapping decentralized control strategy may lead to time delays in the operation of the subsystems and thus affect the control performance of the control systems. The influence of the time-lag phenomenon in the control system can be overcome by using the advice of scholars [39-46].

\section{Data Availability}

The data used to support the study are available from the corresponding authors upon request.

\section{Conflicts of Interest}

The authors declare that they have no conflicts of interest.

\section{Acknowledgments}

This study was supported by the Anhui Provincial Natural Science Foundation (2008085QE245), the Natural Science Research Project of Higher Education Institutions in Anhui Province (KJ2019A0747, KJ2019A0748, and KJ2020A0490), the National Key Research and Development Program of China (2016YFC0701507-2), the Project of Science and Technology Plan of Department of Housing and UrbanRural Development of Anhui Province (2019YF-029 and 2020-YF20), the Doctoral Startup Foundation of Anhui Jianzhu University (2017QD05, 2020QDZ07, and 2020QDZ38), and the College Student Innovation and Entrepreneurship Training Program of Anhui Province (S202010878014 and S202010878049). 


\section{References}

[1] A. Pippi, P. Bernardes Júnior, S. Avila, M. De Morais, and G. Doz, "Dynamic response to different models of adjacent coupled buildings," Journal of Vibration Engineering \& Technologies, vol. 8, no. 1, pp. 247-256, 2019.

[2] T. He and N. Jiang, "Substructure shake table test for equipment-adjacent structure-soil interaction based on the branch mode method," The Structural Design of Tall and Special Buildings, vol. 28, no. 2, p. 1573, 2019.

[3] M. Basili, M. De Angelis, and D. Pietrosanti, "Defective two adjacent single degree of freedom systems linked by springdashpot-inerter for vibration control," Engineering Structures, vol. 188, pp. 480-492, 2019.

[4] K. T. Chau, X. X. Wei, X. Guo, and C. Y. Shen, "Experimental and theoretical simulations of seismic poundings between two adjacent structures," Earthquake Engineering \& Structural Dynamics, vol. 32, no. 4, pp. 537-554, 2003.

[5] P. C. Polycarpou and P. Komodromos, "Earthquake-induced poundings of a seismically isolated building with adjacent structures," Engineering Structures, vol. 32, no. 7, pp. 1937-1951, 2010.

[6] Y. Q. Ni, J. M. Ko, and Z. G. Ying, "Random seismic response analysis of adjacent buildings coupled with non-linear hysteretic dampers," Journal of Sound and Vibration, vol. 246, no. 3, pp. 403-417, 2001.

[7] Z. Yang, Y. L. Xu, and X. L. Lu, "Experimental seismic study of adjacent buildings with fluid dampers," Journal of Structural Engineering, vol. 129, no. 2, pp. 197-205, 2003.

[8] Z. G. Ying, Y. Q. Ni, and J. M. Ko, "Stochastic optimal coupling-control of adjacent building structures," Computers \& Structures, vol. 81, no. 30-31, pp. 2775-2787, 2003.

[9] A. V. Bhaskararao and R. S. Jangid, "Seismic response of adjacent buildings connected with friction dampers," Bulletin of Earthquake Engineering, vol. 4, no. 1, pp. 43-64, 2006.

[10] J. Kim, J. Ryu, and L. Chung, "Seismic performance of structures connected by viscoelastic dampers," Engineering Structures, vol. 28, no. 2, pp. 183-195, 2006.

[11] H. P. Zhu, D. D. Ge, and X. Huang, "Optimum connecting dampers to reduce the seismic responses of parallel structures," Journal of Sound and Vibration, vol. 330, no. 9, pp. 1931-1949, 2011.

[12] M. Basili and M. De Angelis, "Optimal passive control of adjacent structures interconnected with nonlinear hysteretic devices," Journal of Sound and Vibration, vol. 301, no. 1-2, pp. 106-125, 2007.

[13] R. E. Christenson, B. F. Spencer Jr, and E. A. Johnson, "Semiactive connected control method for adjacent multidegree-of-freedom buildings," Journal of Engineering $\mathrm{Me}$ chanics, vol. 133, no. 3, pp. 290-298, 2007.

[14] S. D. Bharti, S. M. Dumne, and M. K. Shrimali, "Seismic response analysis of adjacent buildings connected with MR dampers," Engineering Structures, vol. 32, no. 8, pp. 2122-2133, 2010.

[15] N. Gunasekaran, R. Saravanakumar, and M. Zhu, "Exponential sampled-data control for T-S fuzzy systems: application to Chua's circuit," International Journal of Systems Science, vol. 50, no. 16, pp. 2979-2992, 2019.

[16] N. Gunasekaran, S. Srinivasan, G. Zhai, and Q. Yu, "Dynamical analysis and sampled-data stabilization of memristor-based Chua's circuits," IEEE Access, vol. 9, pp. 25648-25658, 2021.

[17] N. Gunasekaran and M. S. Ali, "Design of stochastic passivity and passification for delayed BAM neural networks with markov jump parameters via non-uniform sampled-data control," Neural Processing Letters, vol. 53, no. 1, pp. 391-404, 2021.

[18] M. S. Ali, R. Agalya, S. Saroha et al., "Leaderless consensus of non-linear mixed delay multi-agent systems with random packet losses via sampled-data control," International Journal of Control Automation and Systems, vol. 18, no. 5, pp. 1885-1893, 2020.

[19] N. Gunasekaran, M. S. Ali, and S. Pavithra, "Finite-time $\$ \$ L_{-}$ linfty \$\$ performance state estimation of recurrent neural networks with sampled-data signals," Neural Processing Letters, vol. 51, no. 2, pp. 1379-1392, 2020.

[20] N. Gunasekaran and Y. H. Joo, "Robust sampled-data fuzzy control for nonlinear systems and its applications: free-weight matrix method," IEEE Transactions on Fuzzy Systems, vol. 27, no. 11, pp. 2130-2139, 2019.

[21] M. S. Ali, N. Gunasekaran, and Q. Zhu, "State estimation of T-S fuzzy delayed neural networks with Markovian jumping parameters using sampled-data control," Fuzzy Sets \& Systems, vol. 306, pp. 87-104, 2017.

[22] N. Gunasekaran, R. Saravanakumar, Y. H. Joo, and H. S. Kim, "Finite-time synchronization of sampled-data T-S fuzzy complex dynamical networks subject to average dwell-time approach," Fuzzy Sets and Systems, vol. 374, pp. 40-59, 2019.

[23] F. Palacios-Quiñonero, J. Rubió-Massegú, J. M. Rossell, and H. R. Karimi, "Semiactive-passive structural vibration control strategy for adjacent structures under seismic excitation," Journal of the Franklin Institute, vol. 349, no. 10, pp. 30033026, 2012.

[24] Y. Wang, J. P. Lynch, and K. H. Law, "Decentralized $\mathscr{H} \infty$ controller design for large-scale civil structures," Earthquake Engineering \& Structural Dynamics, vol. 38, no. 3, pp. 377401, 2009.

[25] M. Syed Ali, M. Usha, O. M. Kwon, N. Gunasekaran, and G. Kumar Thakur, " $\mathscr{H} \infty /$ passive non-fragile synchronisation of Markovian jump stochastic complex dynamical networks with time-varying delays," International Journal of Systems Science, vol. 12, pp. 1-14, 2020.

[26] Y.-C. Wang and C.-J. Chien, "Decentralized adaptive fuzzy neural iterative learning control for nonaffine nonlinear interconnected systems," Asian Journal of Control, vol. 13, no. 1, pp. 94-106, 2011.

[27] H. Hao and J. Shen, "Estimation of relative displacement of two adjacent asymmetric structures," Earthquake Engineering \& Structural Dynamics, vol. 30, no. 1, pp. 81-96, 2015.

[28] M. Gudarzi and H. Zamanian, "Application of active vibration control for earthquake protection of multi-structural buildings," International Journal of Scientific Research in Knowledge, vol. 1, no. 11, pp. 502-513, 2013.

[29] J. Rubió-Massegú, F. Palacios-Quiñonero, J. M. Rossell, and H. R. Karimi, "A novel iterative linear matrix inequality design procedure for passive inter-substructure vibration control," Applied Sciences, vol. 10, no. 17, p. 5859, 2020.

[30] F. Palacios-Quiñonero, J. Rubió-Massegú, J. M. Rossell, and H. R. Karimi, "Static output-feedback vibration control of seismically excited buildings: an effective multistep approach," Vibration Control and Actuation of Large-Scale Systems, vol. 2020, pp. 157-184, 2020.

[31] F. Palacios-Quiñonero, J. Rubió-Massegú, J. M. Rossell, and H. R. Karimi, "An effective computational design strategy for Ho vibration control of large structures with information constraints," Engineering Structures, vol. 171, pp. 298-308, 2018. 
[32] F. Palacios-Quiñonero, J. M. Rossell, and H. R. Karimi, "Emidecentralized strategies in structural vibration control," Modeling, Identification and Control: A Norwegian Research Bulletin, vol. 32, no. 2, pp. 57-77, 2011.

[33] X.-B. Chen, W.-B. Xu, T.-Y. Huang, X.-Y. Ouyang, and S. S. Stankovic, "Pair-wise decomposition and coordinated control of complex systems," Information Sciences, vol. 185, no. 1, pp. 78-99, 2012.

[34] C. Qu, L. Huo, H. Li, and Y. Wang, "A double homotopy approach for decentralized Ho control of civil structures," Structural Control and Health Monitoring, vol. 21, no. 3, pp. 269-281, 2014.

[35] C. S. Mehendale and K. M. Grigoriadis, "A double homotopy method for decentralised control design," International Journal of Control, vol. 81, no. 10, pp. 1600-1608, 2008.

[36] H. N. Fadhilah, G. Zhai, D. Adzkiya, and E. Apriliani, "H_o state feedback for linear systems with decentralized control inputs," Science Nature, vol. 2, no. 4, pp. 219-231, 2020.

[37] H. N. Fadhilah, D. K. Arif, Fatmawati et al., "Centralized and decentralized $\mathrm{H} \infty$ controller design for storey building systems using matrix inequality approach," in Proceedings of the International Conference on Electrical Engineering and Informatics (ICEEI), pp. 105-110, Bandung, Indonesia, July 2019.

[38] X.-B. Chen and S. S. Stanković, "Decomposition and decentralized control of systems with multi-overlapping structure," Automatica, vol. 41, no. 10, pp. 1765-1772, 2005.

[39] M. S. Ali, G. Narayanan, S. Saroha et al., "Finite-time stability analysis of fractional-order memristive fuzzy cellular neural networks with time delay and leakage term," Mathematics and Computers in Simulation, vol. 185, pp. 468-485, 2021.

[40] M. S. Ali and M. Hymavathi, "Synchronization of fractional order neutral type fuzzy cellular neural networks with discrete and distributed delays via state feedback control," Neural Processing Letters, vol. 53, no. 2, pp. 1-29, 2021.

[41] M. S. Ali, M. Usha, A. Alsaedi, and B. Ahmad, "Synchronization of stochastic complex dynamical networks with mixed time-varying coupling delays," Neural Processing Letters, vol. 52, no. 2, pp. 1233-1250, 2020.

[42] M. S. Ali, M. Usha, Q. Zhu et al., "Synchronization analysis for stochastic T-S fuzzy complex networks with markovian jumping parameters and mixed time-varying delays via impulsive control," Mathematical Problems in Engineering, vol. 5, pp. 1-27, 2020.

[43] M. Syed Ali, R. Agalya, V. Shekher et al., "Non-fragile sampled data control for stabilization of non-linear multi-agent system with additive time varying delays, Markovian jump and uncertain parameters," Nonlinear Analysis: Hybrid Systems, vol. 36, p. 10830, 2020.

[44] M. S. Ali, R. Vadivel, A. Alsaedi, and B. Ahmad, "Extended dissipativity and event-triggered synchronization for T-S fuzzy Markovian jumping delayed stochastic neural networks with leakage delays via fault-tolerant control," Soft Computing, vol. 24, no. 5, pp. 3675-3694, 2020.

[45] M. S. Ali, N. Gunasekaran, and O. M. Kwon, "Delaydependent $H \infty$ performance state estimation of static delayed neural networks using sampled-data control," Neural Computing and Applications, vol. 30, no. 2, pp. 539-550, 2018.

[46] M. S. Ali, R. Vadivel, O. M. Kwon, and K. Murugan, "Event triggered finite time $\$ \$ \mathrm{H}_{-}\{$\infty\} $\$ \mathrm{H} \infty$ boundedness of uncertain markov jump neural networks with distributed time varying delays," Neural Processing Letters, vol. 49, no. 3, pp. 1649-1680, 2019. 